\section{Pode-se amar a televisão?}

\author{
Arlindo Machado
}

No catálogo da quinta edição do Invideo, evento que ocorre todos os anos em Milão para mostrar e discutir a produção audiovisual italiana, os curadores da mostra de televisão começam assim o seu texto de apresentação: "Temos que confessar que este é um ato de amor pela televisão. Sabemos que não é fácil dizer isso em voz alta. É sempre mais fácil confessar nosso amor pelo cinema..." (Candalino e Ciorciolini, 1998: 96). De fato, não soa muito inteligente dizer-se apaixonado pela televisão. Se a confissão de amor pela literatura ou por quaisquer outras formas sofisticadas de arte funciona como uma demonstração (às vezes também uma impostação) de educação, refinamento e elevação do espirito, a paixão pela televisão é, em geral, interpretada como sintoma de ignorância, quando não de desequilíbrio mental. Mas por que as coisas são assim?

Dizer que na televisão só existe banalidade é um duplo equívoco. Em primeiro lugar, há o erro de considerar que as coisas são muito diferentes fora da televisão. O fenômeno da banalização é resultado de uma apropriação industrial da cultura e pode ser hoje estendido a toda e qualquer forma de produção intelectual do homem. Exemplo particularmente sintomático desse fenômeno é a transformação das livrarias, tradicionais pólos de encontro das camadas intelectuais, em supermercados da cultura, especializados em bestsellers e digestivos, para onde acorre um público de massa, que lota seus carrinhos de compra com uma subliteratura de consolo e manuais de auto-ajuda. Não é muito diferente o que acontece no cinema, hoje largamente infectado pelos blockbusters de Hollywood e voltado prioritariamente para a produção de descartáveis para as salas de exibição em shopping centers. Por que deveria a televisão pagar sozinha pela culpa de uma mercantilização generalizada da cultura?

Por outro lado, da mesma forma como, na contramão das tendências hegemônicas, continua existindo uma literatura de insubmissão ao gosto padronizado e um cinema de expressão de inquietudes não catalogadas, existe também vida inteligente na televisão. Uma pesquisa seriamente conduzida pode demonstrar que o acervo de obras criativas e inquietantes produzido pela televisão não é maior nem menor que aquele acumulado em outras linguagens. Ao longo de seus mais de cinqüenta anos de história, a televisão deu mostras de ser um sistema expressivo suficientemente amplo e denso para dar forma a trabalhos complexos e também abriu espaço para a intervenção de mentalidades pouco convencionais, gente como Krzysztof Kieslówski, Raúl Ruiz, Jean-Christophe Averty, Nam June Paik, Jean-Luc Godard, Robert Altman, Rainer Werner Fassbinder, Sandra Kogut, Roberto Rossellini, Peter Watkins, Henri-Georges Clouzot, Peter Greenaway, Zbigniew Rybczynski, Samuel Beckett, Alfred Hitchcock, Ingmar Bergman, Eenie Kovacs, Peter
"À guisa de prefácio", texto de introdução ao livro A televisão

levada a sério (Editora Senac-SP, 248 pp,). Reproduzido pela Novos Olhares com autorização do autor.

Arlindo Machado é professor e pesquisador junto à ECA/USP e à PUC/SP. 
Sellars, Gianni Toti, Miklós Jancsó, Orson Welles, Glauber Rocha, David Lynch, Guel Arraes, Federico Fellini, Robert Wilson, Alexander Kluge e tanto outros que ajudaram a construir uma ética e uma estética da televisão.

Eis porque se pode amar a televisão sem necessariamente precisar fazer concessões a qualquer espécie de banalidade e sem correr o risco de se passar por ignorante. Tudo é uma questão de mudança de enfoque. Em lugar de prestar atenção apenas às formas mais baixas de televisão, a idéia é deslocar o foco para a diferença iluminadora, aquela que faz expandir as possiblidades expressivas desse meio. Num levantamento preliminar que fiz para este volume pude arrolar cerca de duzentos programas, produzidos em várias partes do mundo, que podem ser considerados dignos da atenção da parcela mais inteligente do público e cujo conhecimento é imprescindível a todos aqueles que se dedicam seriamente à abordagem da televisão. Essa lista é apenas um primeiro passo na direção de uma reconsideração do papel da televisão na constituição da cultura contemporânea e deverá ser continuada com a inevitável descoberta de outras preciosidades até agora ignoradas pela parte pensante da sociedade.

Esquematicamente, pode-se abordar a televisão (da mesma forma que qualquer outro meio) de duas formas distintas. Pode-se tomá-la como um fenômeno de massa, de grande impacto na vida social moderna, e submetê-la a uma análise de tipo sociológico, para verificar a extensão de sua influência. Neste caso, a discussão sobre a qualidade da programação tem pouca aplicabilidade. $\mathrm{O}$ que vale é a amplitude das experiências e a magnitude de suas repercussões. É por isso que abundam nesse tipo de abordagem os estudos baseados em rating (sondagem da quantidade de audiência) e é por isso também que, no geral, as abordagens sociológicas acabam coincidindo de forma particularmente perigosa com as pesquisas mercadológicas. Mas também se pode abordar a televisão sob um outro viés, como um dispositivo audiovisual através do qual uma civilização pode exprimir a seus contemporâneos os seus próprios anseios e dúvidas, as suas crenças e descrenças, as suas inquietações, as suas descobertas e os vôos de sua imaginação. Aqui, a questão da qualidade da intervenção passa a ser fundamental.

Minhas preocupações com os problemas relacionados com criatividade e inteligência em televisão nasceram do trabalho docente. Como professor do curso de Rádio e Televisão na Universidade de São Paulo, sempre me senti incomodado com a falta de referências sofisticadas que pudessem servir de farol e bússola aos alunos que o se formam nessas especialidades e que vão em seguida atuar no mercado profissional. $\mathrm{O}$ meu parâmetro de comparação era o curso de Cinema e Vídeo. Para passar pelo processo de seleção e ingressar neste último curso, os alunos tinham de comprovar um conhecimento básico da história desses meios. Depois, ao longo do curso, os alunos aprendiam a fazer cinema e vídeo através do contato freqüente com as obras mais importantes produzidas nessas linguagens. Não se admitia como de resto continua-se a não admitir - um profissional de cinema e vídeo, seja ele realizador, crítico ou docente, que não tivesse mantido contato com $\mathrm{o}$ repertório fundamental de obras produzidas nesses meios (pensamos em coisas como os filmes de Griffith, Welles, Eisenstein, Godard, Resnais, Kubrick, Rocha e os vídeos de Viola, Paik, Hill, Cahen e Toti).

Com os alunos de Rádio e Televisão, todavia, isso não acontecia, simplesmente porque não existia um trabalho anterior de avaliação da história desses meios, conduzido por gerações de críticos e pesquisadores competentes, 
que pudesse indicar um repertório fundamental de trabalhos televisuais. Que valores éticos e estéticos poderíamos então cultivar nesses alunos, se não existiam referências positivas (ou negativas, mas no sentido produtivo do termo) para nelas nos basearmos? Que espécie de televisão poderíamos esperar de gerações de profissionais formadas com base apenas num pragmatismo desinformado e que nunca tiveram contato com produções qualitativas? Aos poucos, começou a ficar claro que as abordagens sociológicas convencionais não eram suficientes quando a questão a ser enfrentada era não apenas o diagnóstico da presença da televisão no mundo, mas os valores a partir dos quais poderíamos intervir produtivamente no processo televisual. No fundo, o desafio pedagógico básico era forjar uma idéia de televisão com a qual pudéssemos nos identificar, de modo a poder colocá-la em prática no trabalho de formação das mentalidades criativas que iriam fazer a televisão do futuro.

Existem muitas teorias - algumas brilhantes, outras nem tanto - sobre o que é ou o que pode ser a televisão. Algumas delas imaginam a televisão intrinsicamente ligada à vida cotidiana (Ellis, 1985), outras à cultura popular (Fiske, 1987), outras ao espaço público (Wolton, 1990), outras ainda a mecanismos de mediação entre emissores e receptores (Martín-Barbero, 1993). São teorias interessantes, quando tomadas seriamente. Nos últimos anos, entretanto, a discussão sobre televisão, sobretudo no Brasil, desceu a um nível de ingenuidade lastimável, em razão principalmente da contaminação da área por um sub-sociologismo repleto de chavões, que chegou ao extremo de sugerir que as formas mais degradantes de televisão "refletem" (a velha tese da "reflexão") a degeneração social ou as mazelas da desigualdade econômica, funcionando portanto como um sintoma ruidoso do estado de convulsão dos excluídos. Daí à aceitação e à apologia do lixo televisual falta apenas um passo. Na verdade, a associação entre crises sociais e modelos degenerados de televisão é ingênua e equivocada, pela simples razão de que tais modelos não são criados em situações de crises: eles são importados de países ricos, sobretudo dos EUA, e implantados por decisão exclusiva dos profissionais da área e dos setores econômicos que os financiam.

Na minha opinião, a televisão é $e$ será aquilo que nós fizermos dela. Nem ela, nem qualquer outro meio, estão predestinados a ser qualquer coisa fixa. Ao decidir o que vamos ver ou fazer na televisão, ao eleger as experiências que vão merecer a nossa atenção e o nosso esforço de interpretação, ao discutir, apoiar ou rejeitar determinadas políticas de comunicação, estamos, na verdade, contribuindo para a construção de um conceito e uma prática de televisão. $\mathrm{O}$ que esse meio é ou deixa de ser não é, portanto, uma questão indiferente às nossas atitudes com relação a ele. Nesse sentido, muitos discursos sobre a televisão às vezes me parecem um tanto estacionários ou conformistas, pois negligenciam o potencial transformador que está implicado nas posturas que nós assumimos com relação a ela; e "nós", aqui, abrange todos os envolvidos no processo: produtores, consumidores, críticos, formadores etc.

Uma palavra-chave nas discussões mais recentes sobre televisão é qualidade. Alguns autores e alguns eventos nacionais ou internacionais instituíram, inclusive, o termo quality television (televisão de qualidade) para designar o novo foco de interesse. Eu particularmente não gosto dessa expressão, pois o acréscimo de um adjunto adnominal à palavra televisão produz uma discriminação que pode ser nociva à própria idéia que se quer defender. De uma forma geral, ninguém fala de "literatura de qualidade", nem de "cinema de qualidade", nem de 
"música de qualidade", uma vez que nos parece óbvio que só o que tem qualidade é verdadeiramente literatura, cinema ou música. Por que deveria ser diferente com a televisão? Ademais, a adoção de uma expressão restritiva para designar uma certa modalidade de televisão poderia reforçar um equívoco já bastante disseminado, segundo o qual a televisão, "por natureza", não tem qualidades; daí a necessidade de caracterizar a qualidade em televisão como um "acréscimo", uma situação especial, uma espécie de desvio da norma. O objetivo não é criar um gueto de qualidade que possa existir isolado, no meio de um mar de mediocridade. Pe contrário, o objetivo é fazer com que a idéia de qualidade possa contaminar tanto a produção quanto a recepção de televisão como um todo, a ponto do adjunto e da discriminação se tomarem desnecessários. Ademais, a expressão televisão de qualidade nem sempre é utilizada no mesmo sentido por todos. Para alguns, ela pode estar servindo apenas de rótulo para designar uma televisão meramente pedagógica, segundo o modelo das televisões estatais oficialmente encarregadas da educação infanto-juvenil, enquanto para as forças mais conservadoras, ela pode estar servindo também de bandeira para a defesa de valores moralistas na televisão. O público mais careta, por exemplo, que está constantemente reivindicando restrições à exploração de sexo, violência e palavrão na tela, também chama de "qualitativa" a televisão que eles querem: uma televisão asséptica, destilada dos problemas e desligada da vida real.

Isso não quer dizer que o conceito de qualidade não possa ser tomado como uma bússola para se fazer, loentender e apreciar televisão. O importante é saber distinguir entre os diversos empregos dessa palavra e também não cair na cilada de explicá-la de forma ingênua ou apressada.

Alguém já definiu a liberdade da seguinte maneira: uma coisa difícil de explicar, quase impossível de conceitualizar, mas muito fácil de compreender o que significa, principalmente quando ela nos falta. Creio que se pode considerar da mesma maneira a qualidade em televisão. 